\title{
System for Primary Care Professionals
}

National Cancer Institute

\section{Source}

National Cancer Institute. System for Primary Care Professionals. NCI Thesaurus. Code C19052.

Computer or Web-based programs that permit the primary care professional to screen, assess, and monitor the outcome of patient interventions or training/education programs for students. 